\title{
Role of Pterostilbene in Metabolic Diseases through SIRT1 pathway- A Review
}

\author{
Rashmi Patil ${ }^{1, a, *}$, Urmila Aswar ${ }^{1, b}$ \\ ${ }^{1}$ Department of Pharmacology, Poona College of Pharmacy, Bharati Vidyapeeth (Deemed to be University), Erandwane, Pune-411038, India. \\ *Corresponding author

\begin{tabular}{|c|c|}
\hline R T I C L E I N F O & B S T R A C T \\
\hline $\begin{array}{l}\text { \#This study was presented as an online } \\
\text { presentation at the } 2^{\text {nd }} \text { International } \\
\text { Journal of Agriculture - Food Science } \\
\text { and Technology (TURJAF 2021) } \\
\text { Gazimağusa/Cyprus } \\
\text { Research Article } \\
\text { Received : 02/12/2021 } \\
\text { Accepted : 27/12/2021 } \\
\text { Keywords: } \\
\text { Pterostilbene } \\
\text { Diabetes } \\
\text { Obesity } \\
\text { Inflammation } \\
\text { Insulin resistance }\end{array}$ & $\begin{array}{l}\text { Pterostilbene (PTE) (3-5 dimethoxy-4-hydroxy-trans-stilbenes) is an analogue of resveratrol. It is } \\
\text { extracted and isolated from a natural source of the heartwood of Pterocarpus marsupium Roxb., red } \\
\text { grape skin, and blueberries (Vaccinium spp.). Substantial evidence suggested that PTE displayed } \\
\text { numerous preventive and therapeutic properties in many metabolic disorders such as diabetes and } \\
\text { obesity. Metabolic diseases result in Insulin resistance (IR) which advances to impaired sensitivity } \\
\text { to insulin-mediated glucose disposal. The prominent role of SIRT (silent information regulator } \\
\text { proteins) is now getting emphasized in metabolic disorders. SIRT1 represses Uncoupling protein } 2 \\
\text { (UCP2) expressions which are further responsible for improving synthesis of ATP from glucose. } \\
\text { This results in improving glucose utilization and insulin secretion, thus preventing IR. SIRT1 also } \\
\text { exhibits prominent role in facilitating fatty acid mobilization thereby inhibiting adiposity. Metabolic } \\
\text { disorders are therefore the consequences of SIRT1 downregulation. Pterostilbene, being a SIRT1 } \\
\text { activator, increases insulin sensitivity reduces adiposity, therefore can prove to be beneficial in } \\
\text { diabetes as well as obesity. The review summarizes therapeutic effects portrayed by Pterostilbene } \\
\text { via the SIRT1 pathway in metabolic diseases. }\end{array}$ \\
\hline
\end{tabular}

\section{Introduction}

Diabetes and Obesity are global health problems affecting various populations and is common in all age groups, gender, and ethnicity. Their prevalence is on the surge with the estimation of $25.3 \%$ (360 million) for diabetes and $44.9 \%$ for obesity in 2030 (Ampofo \& Boateng, 2020). Diabetes mellitus (DM) is a disease characterized of inadequate insulin regulation which leads to disorganization of carbohydrate, protein, and fat metabolism. While obesity is body mass index above 30 $\mathrm{kg} / \mathrm{m}^{2}$ which is associated with chronic low-grade inflammation and is an important parameter to the pathogenesis of IR (Aswar et al., 2019). DM and obesity thereupon result in IR which advances to impaired sensitivity to insulin-mediated glucose disposal. This leads to intolerance to a glucose load causing hyperglycemia,hyperinsulinemia, increased very lowdensity lipoprotein (VLDL), decreased very high-density lipoprotein (VHDL), and hypertension.

\section{Role of SIRT1 in metabolic diseases}

The prominent role of SIRT (silent information regulator proteins) is getting emphasized concerning metabolic disorders. SIRT is a group of NAD-dependent Class III histone deacetylases causing deacetylation of histone or non-histone proteins. It results in the transfer of the acetyl group from acetyl lysine residue of histone to the ADP-ribose moiety of NAD+, producing nicotinamide, 2'O-acetyl ADP ribose, and deacetylated proteins (Chong et al., 2012). Seven mammalian SIRT proteins have been identified as SIRT1 to SIRT7. Research has shown that SIRT-1 protein is involved in regulating cellular protection against oxidative stress in diabetes (Chong et al., 2012). Increased SIRT 1 expression is stated to improve glucose utilization, insulin secretion and inhibition of IR (Cao et al., 2016), regulation of inflammatory responses. This raised the interest in the use of SIRT1 analogs in the management of a variety of diseases including diabetes (Ramadori et al., 2011) and obesity (Xu et al., 2016). Hence, SIRT1 becomes a newer target to overcome diabetes, obesity, IR and inflammation. SIRT1 represses 
UCP2 expression which is responsible for inhibiting the synthesis of ATP from glucose by uncoupling mitochondrial respiration. Hence SIRT1 expression improves ATP synthesis from glucose thereby improving glucose utilization, insulin secretion and inhibiting IR. In obesity, expression of SIRT1 is found to be reduced, it is observed that fatty acid mobilization from white adipose tissue is compromised in SIRT1 deficient mice (Picard et al., 2010). Thus it can be stated that SIRT1 expression is responsible for inhibiting adiposity (Xu et al., 2016)

\section{PTE as SIRT1 activator}

PTE (3-5 dimethoxy-4-hydroxy-trans-stilbene) is an aromatic hydrocarbon belonging to one of the polyphenolic compounds called stilbenoids (Figure 1).

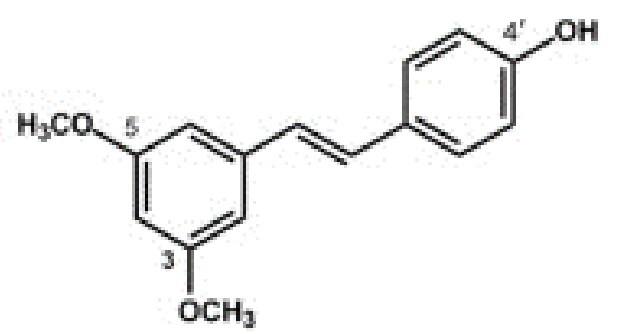

IUPAC name-3-5 dimethoxy-4-hydroxy-trans-stilbene Figure 1. Structure of Pterostilbene

PTE potrays high liposolubility and increased Blood brain barrier (BBB) permeability due to the presence of two more methoxy groups on the A-benzene ring as compared to resveratrol (Deng et al., 2015). It has a molecular weight of 256.3 hence gets rapidly absorbed and distributed in the body (Kapetanovic et al., 2011). This significantly results in increased cell membrane permeability, higher bioavailability, bioactivity, stability, longer half-life, and lower toxicity which may have good prospects in the future for clinical application (Kapetanovic et al., 2011). The major factor affecting PTE dissolution is its poor water solubility but gets easily dissolved in ethanol. Various suspending agents like Carboxy methylcellulose, $\beta$ Cyclodextrin, Tween 80 can be incorporated. It gets excreted in the form of glucoronic acid and conjugates with its binding metabolites (Remsberg et al., 2008). In this review, we systematically introduce the emerging role of PTE in metabolic disorders such as diabetes and obesity through the SIRT1 pathway. SIRT1 shows its beneficial effects mediated through various probable factors such as UCP2, Nuclear factor erythroid 2-

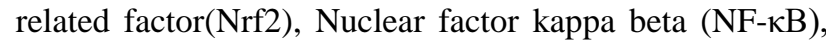
Peroxisome proliferator- activated receptor gamma (PPARY) and Peroxisome proliferator-activated receptorgamma coactivator $\alpha$. (PGC-1 $\alpha$ ). The downregulation of SIRT1 in metabolic conditions hampers its ability to block $\mathrm{UCP} 2$, Nrf2 and NF- $\mathrm{BB}$. Increased expression of UCP2 negatively regulates insulin secretion, resulting in IR. SIRT1 is master regulator of inflammatory responses by inhibiting Nrf2 and $\mathrm{NF}-\kappa \mathrm{B}$ which regulate the levels of proinflammatory cytokines (TNF- $\alpha, \mathrm{IL}-1 \beta, \mathrm{IL}-16, \mathrm{IL}-8)$. PPARY and PGC-1 $\alpha$ play important role in mitochondrial biogenesis, lipid and glucose homeostasis and antioxidant defense mechanism,which gets affected by SIRT1 downregulation.

PTE displays wide variety of pharmacological roles which include potent anticancer, hypolipidemic activity, anti-diabetes, cardioprotection and neuroprotection (Remsberg et al., 2008). The probable mechanisms can be corelated to its antioxidant and anti-inflammatory property (Kosuru et al., 2016) (Gómez-Zorita et al., 2015). PTE being SIRT1 activator it potentiates its activity and results in attenuation of metabolic disorders. The probable pathway is depicted is Figure 2.

\section{Sources of PTE}

Pterostilbene was first identified and isolated from Pterocarpus santalinus L. (P. santalinus; sandalwood) in the year,1940(Seshadri, 1972). Few years later many other sources were identified such as $P$. marsupium (Indian kino) (Manickam et al., 1997), Vaccinium berries (Rimando et al., 2004), Vitis vinifera L. (grape vine) (Adrian et al., 2000), and Arachis hypogaea L. (peanut) (Sobolev et al., 2011).

\section{Pterocarpus marsupium Roxb. (Fabaceae)}

Taxonomic position: Order -Fabales; FamilyFabaceae; Subfamily- Faboideae; Tribe -Dalbergieae; Genus -Pterocarpus; Species -P. marsupium.

P. marsupium Roxb. (Fabaceae) is well known in India and neighbouring countries for more than 2000 years. It is comonly known as Malabar kino, Indian kino, Vijayasar, or Venkai.Kino is called as "Bija or Bijasal" (Gamble JS 1935). It is a deciduous tree species with high medicinal value, found in India, in the Western Ghats in the Karnataka-Kerala region, forests of Central India, Nepal, and Sri Lanka. It can grow medium to large, up to $30 \mathrm{~m}$ (98 ft) tall. The tree has multipurpose uses such as for wood, fodder, fuel wood and shade tree in coffee plantations. Every part of the tree has been used for its most versatile medicinal values and a wide spectrum of biological activity. It is a valuable source of unique natural products for development of medicines against various diseases as described below. The leaves of the tree are compound with three to seven oblong leaflets, three to five inches in length, with wavy margins. Medicinally leaves can be applied externally for boils, sores and skin diseases and for treatment of stomach ulcers. Flowers are yellow coloured, fragnant with large pannicles. They are bitter in taste and improve the appetite and cause flatulence and also useful in control of fever (Kitikar et al., 1999). Seed pods are flat, orbicular and winged. Gum is bitter in taste and is used as antipyretic, anthelmintic and tonic to liver. It is useful in treatment of diarrhea, dysentery, leucorrhoea, passive haemorrhages. The surface of bark rough, grey or greyishblack longitudinally fissured, scaly, exfoliated, irregular, fibrous with width of $10-15 \mathrm{~mm}$. The internal colour of older tree bark is blaze pink and it exudes blood-red gum resin. Heartwood in golden yellow and sapwood is pale yellow to white in colour. The bark shows beneficial activity against stomachache, cholera, dysentery, urinary complaints, tongue diseases and toothaches. $P$. marsupium contain pterosupin, pterostilbene, isoliquiritigenin, liquiritigenin, epicatechin, kinotannic acid, kinoin, kinored beta-eudesmol, marsupol, carpusin and marsupinol (Badkhane et al., 2010). 


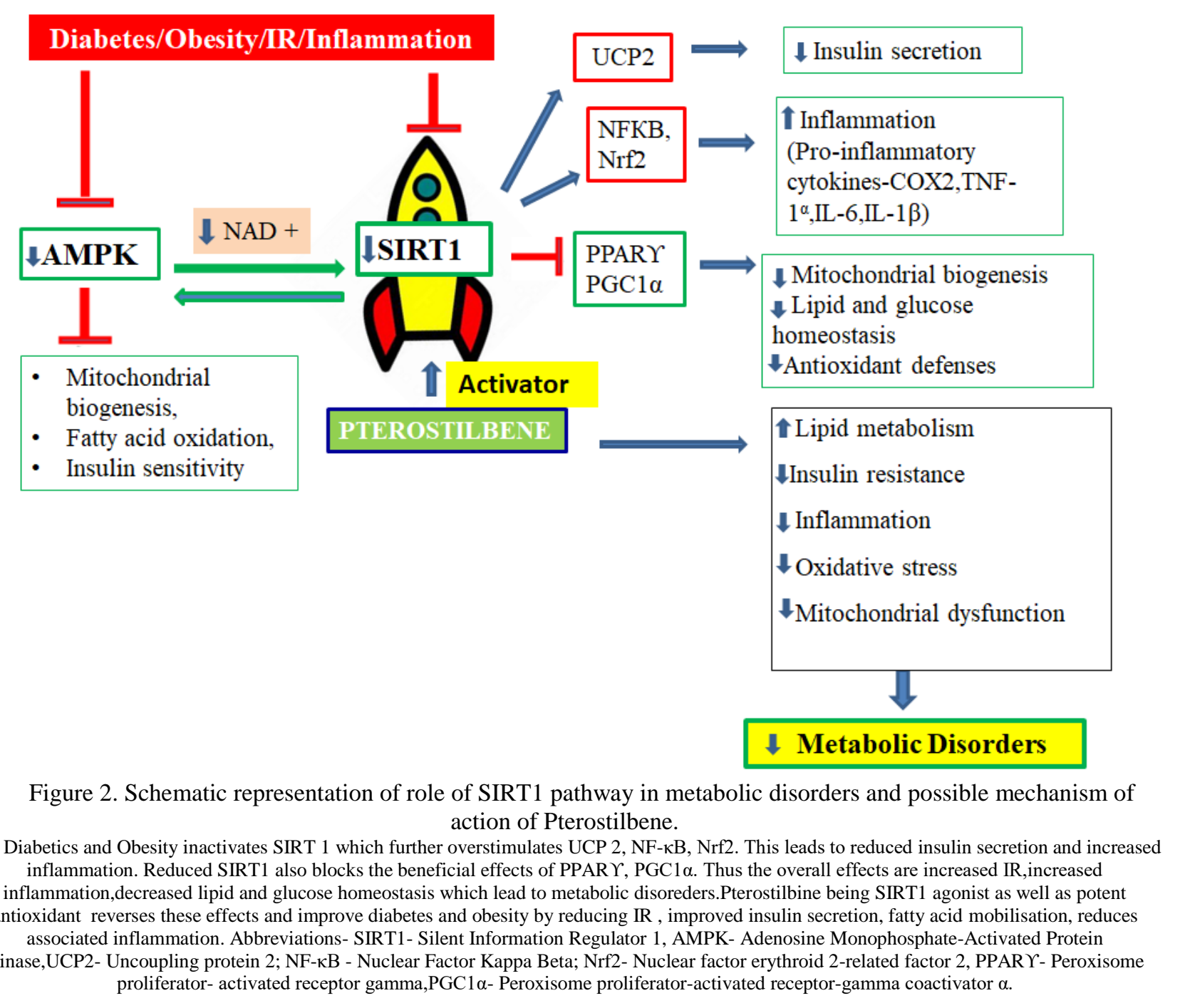

It exhibits a unique feature of beta cell protection and regeneration along with blood glucose reduction(Dhanabal et al., 2006). Many preclinical trials conducted on various species including rats, dogs, and rabbits with induced diabetes. $P$. marsupium reversed the damage to the beta cells leading to complete restoration of normal insulin secretion (Satheesh \& Pari, 2010). It also exhibit PGE2- inhibitory and COX-1/2 selective inhibitory activity which attenuates inflammation (Rizvi \& Mishra, 2013) (Figure 3).

Vaccinium spp (Blueberries and Cranberries)

Vaccinium ashei Reade (Blueberries)

Taxonomic position: Order-Family Ericaceae, Subfamily Vaccinoideae, Genus Vaccinium,

The blueberry belongs to Ericaceae family and genus Vaccinium.The cluster fruited blueberry species are largely confined to the eastern United States containing acidic soil and South America and particularly to Alabama. Two Vaccinium species, V. ashei Reade (rabbiteye blueberry) and $V$. stamineum L. (deerberry), contain pterostilbene (Rimando et al., 2004). In rabbiteye blueberry (V. ashei), every $100 \mathrm{~g}$ of the dried sample contains 9.9-15.1 $\mu \mathrm{g}$ of pterostilbene and deerberry (V. stamineum ) contains about $52 \mu \mathrm{g} / 100 \mathrm{~g}$ dry sample (Rimando et al., 2004). Blueberry fruit are known as "false" berries because they originate from inferior ovaries (Vicente et al., 2007) which rapidly swells after fertilization and remain green with little change in volume. The berry beguns to get more purple with time and with increased sweetness and flavours (Figure 3). Blueberries are deep purple to black, but the bluish colour is due to the glaucous covering(Austin \& Bondari, 1993).

Vaccinium stamineum L.( Deerberry)

Taxonomic position: Order: Ericales, Family: Ericaceae, Genus:Vaccinium, Species: Vaccinium stamineum L. - Deerberry

$V$. stamineum (deerberry), majorly found in the United States and Canada. It is commonly known as deerberry, tall deerberry, squaw huckleberry, high bush huckleberry, buckberry, and southern gooseberry. It is a is a low slender shrub, growing up to 1.5 meters (60 inches or 5 feet) tall. The leaves are alternate, simple, elliptical, entire, 1 to 3 inches long, which have thin blades yellow green in colour with waxy hairy texture. Flowers are Small (1/4 inch), white, bell-shaped with 5 lobes, hanging with five green sepals and bell shaped corolla five in number fused with petals.Fruits are small, purplish-black with a white bloom, edible with tart, sour, bitter, or sweet-spicy taste.Twig is slender, zigzag, green and red turning and pointed.Bark is gray-brown to reddish brown and shreddy in nature (Figure 3 ). The fruit is rich source of vitamins A, C, and E, as well as carbohydrates, protein, fiber, and fat. The chemical 
constituents present are polyphenolic substances including chlorogenic, citric, malic, quinic, acetic, caffeic, pcoumaric, and shikimic acids. It exhibits wide range of pharmacological properties like reduction of blood sugar, serum cholesterol, and triglyceride levels and are demonstrated to be antiallergenic, anti-viral and antiproliferative (Druice and Percival 2003).A noteworthy observation was done by Pezet et.al (1988) that a higher concentration of PTE was found to be presented in grapes infected by fungus in comparison with the healthy skin of grapes.

\section{Vitis vinifera (Grapes)}

Taxonomic position Kingdom-Plantae; CladeTracheophytes; Order-Vitales; Family-Vitacea; GenusVitis; Species-V.vinifera

$V$. vinifera, also know as the common grape vine, is native of mediterranean region,Central Europe and Southwestern Asian. It is commonly called as kalidraksha.
It is s a woody, deciduous vine that climbs by branched tendrils which sprawl horizontally over low-growing shrubs. Leaves are ovate, suborbicular with long stalk. The margin of leaves are bristle and coarsely toothed. Soft pulpy grapes (botanically berries) are grown from the flower which get ripen to sweet taste in summers, which vary in size, form and color. The barks are flaky and shred in strips (Figure 3). Grapes are rich source of resveratrol and its analogue, the flavanol quercetin, catechins, procyanidins, and anthocyanins, etc. It acts as an antioxidant, which are essential for improving a person's appetite and metabolism(Jayaprakasha et al., 2001). Vitis vinifera shows pharmacological activity in treatment of cardiovascular diseases, cognition and neuronal function associated with aging and neurodegenerative disorders, tumor and microbial infection. HPLC study of Darakchasava a traditional Indian herbal medicine shows presence of PTE (Paul et al., 1999).

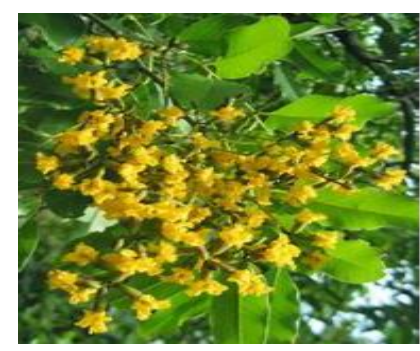

a

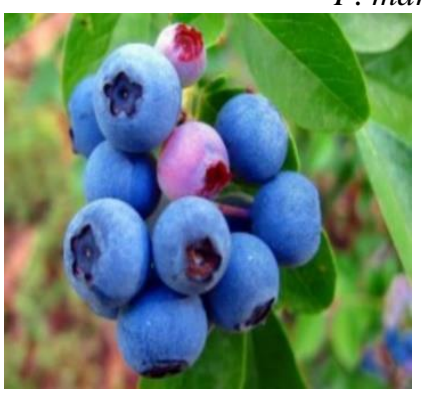

a

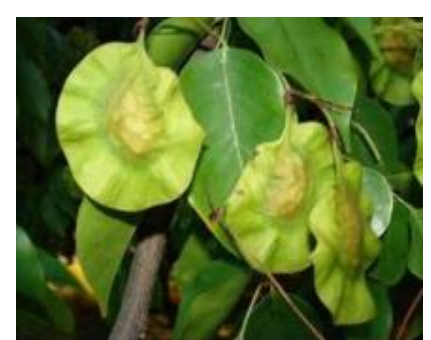

$\mathrm{b}$

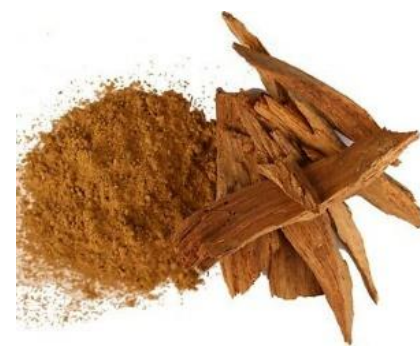

c

P. marsupium Roxb. (Fabaceae), a- flower, b- seed and c- bark

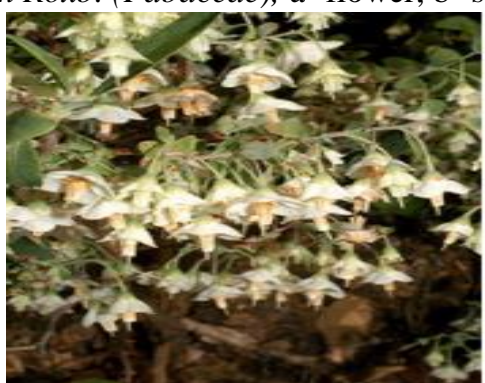

b

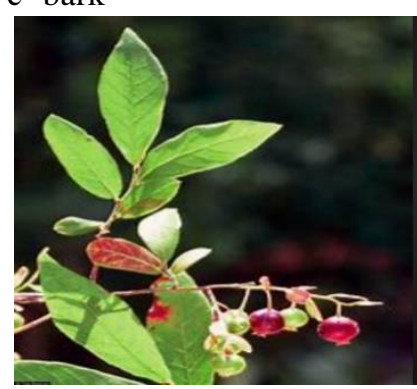

L. ( Deerberry)

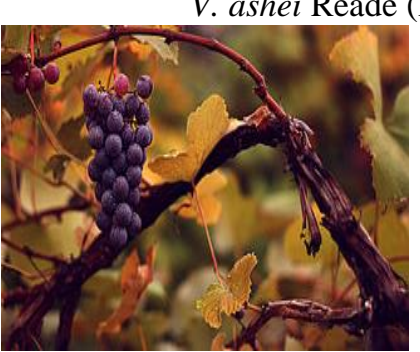

a

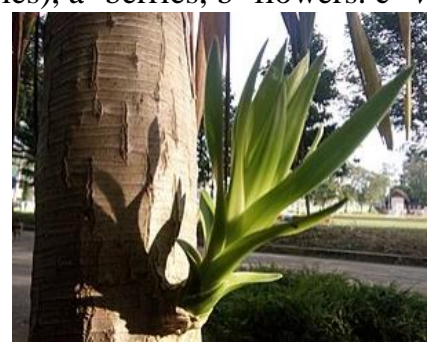

b

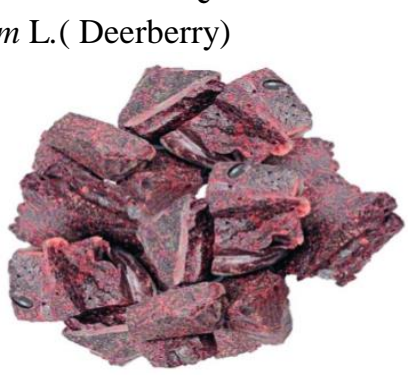

c

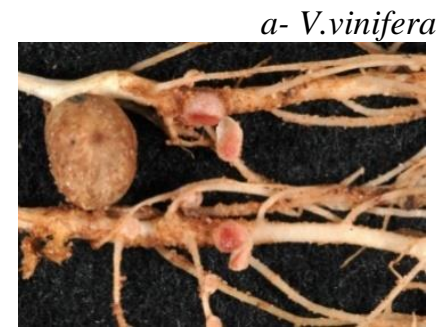

Arachis hypogaea (Peanuts)

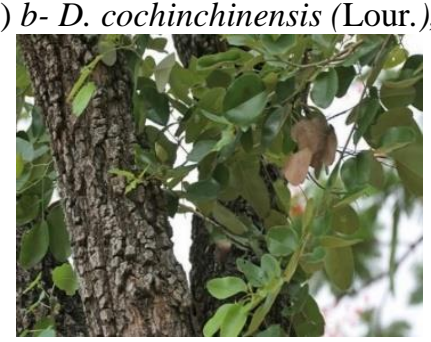

P. santalinus (Sandalwood)

Figure 3. Sources of Pterostilbine 


\section{Dracaena cochinchinensis (Lour.)}

Taxonomic position: Kingdom: Plantae, Order: Asparagales, Family: Asparagaceae, Subfamily: Nolinoideae, Genus: Dracaena, Species: cochinchinensis

PTE is present in the dragon's blood renin derived from D. cochinchinensis (Lour.). It is a bright red resin located at Guangxi and Yunnan provinces of China (Ding et al., 2018), asian tropical forests under the family is Asparagaceae. The tree is evergreen plant which is multibranched, 5 - $15 \mathrm{~m}$ tall (Fan et al., 2014) (Figure 3). The plant is reported for promotion of blood circulation, analgesic, antibacterial, antiinflammatory, antioxidant, antiseptic, antispasmodic, antithrombotic, antitumor, astringent and haemostatic (Liu et al., 2013). It also treats a diverse range of central and peripheral inflammatory diseases such as diabetes, arthritis, colitis, gynecopathy, and allergic dermatitis.

\section{Arachis hypogaea (Peanuts)}

Taxanomic position- Genus-Arachis; Specieshypogaea; Family-Fabaceae

A.hypogaea, or peanut, is a legume grown worldwide and is native to central Brazil. Numerous studies demonstrated that hairy root cultures of peanut which is among the divergent group of plants that contain significant amount of Pterostilbene (Medina-Bolivar et al., 2007). The name hypogaea means "under the earth" is used since the pod containing edible seed grows below the ground. The flowers are bright yellow in colour, with 4-5 petals and 1-3 inches in size. The leaves are elliptically ovate green coloured, 1-3 inches in length with a prominent midvein. Stem is cylindrical and smooth, sturdy erect or prostrate stem which become angular and hairy with age. The pods, grown underground contain one to three seeds covered with thin papery seed coat (Figure 3). Peanut is one of the principal oilseeds and high-quality food on daily basis. The peanut oil has demulcent, emollient, antiinflammatory, aphrodisiac and decoagulant action.

\section{Pterocarpus santalinus (Sandalwood)}

Taxanomic position- Kingdom- Plantae; PhylumTracheophyta; Class:-Equisetopsida C.Agardh ; OrderFabales; Family -Fabaceae; Genus- Pterocarpus; SpeciesPterocarpus santalinus L.f.

The Pterocarpus species is distributed in majorly in peninsular India and Sri Lanka. Common names are Agaru, Red sandalwood, chandan. Sandalwood is a deciduous tree with clear trunk and rounded crown with height of about height of $10 \mathrm{~m}$.The flowers are yellow, densely arranged in branches. The pods are narrowly winged oblilquely orbicular, $3-4 \mathrm{~cm}$ in size.The leaves are alternately arranged and petiolate. The bark is blackish brown, fissured and similar to crocodile skin (Figure 3 ). When the inner part of bark is cut it oozes out red coloured 'santolin' dye. It is used as an astringent, analgesic, antiinflammatory. It shows effective role in treatment of chronic dysentery, burning sensation, vomiting, skin diseases, leprosy, ulcers, fistula and haemorrhages.It shows prominent antidiabetic activity which can be useful in lowering the blood sugar level (Kameswara Rao et al., 2001).

\section{Conclusion}

PTE is found to act through SIRT1 activation and SIRT1 has been proven to be beneficial in treatment of diabetes, IR and inflammation. It is also found to mobilize fatty acids useful for avoidance of obesity. Considering the significant role of Pterostilbene in metabolic diseases and improvement in understanding of its mechanism of action at molecular level, the moiety should be further studied for its clinical use. The present review has overviewed the beneficial effects of PTE and its sources.

\section{Acknowledgement}

The authors would like to acknowledge Dr. A.P.Pawar, Principal, PCP, BVDU for providing the necessary facilities to prepare the manuscript.

\section{References}

Adrian M, Jeandet P, Douillet-Breuil C, Tesson L, \& Bessis R. 2000. Stilbene content of mature Vitis vinifera berries in response to UV-C elicitation. Journal of Agricultural and Food Chemistry, 48(12), 6103-6105. doi.org/10.1021/jf0009910

Ampofo G, Boateng B. 2020. Beyond 2020: Modelling obesity and diabetes prevalence. Diabetes Research and Clinical $\begin{array}{lll}\text { Practice, } & 167, & 108362 .\end{array}$ doi.org/10.1016/j.diabres.2020.108362

Aswar U, Patil R, Bodhankar S. 2019. Review on the induction of obesity in laboratory animals. Diabesity, 5(4), 25-31. doi.org/10.15562/diabesity.2019.58

Austin E, Bondari K. 1993. Fruit Quality Characteristics of Five Rabbiteye Blueberry Cultivars and Clones. In Acta Horticulturae (Issue 345, pp. 133-140). doi.org/10.17660/actahortic.1993.345.18

Cao Y, Jiang X, Ma H, Wang Y, Xue P, Liu Y. 2016. SIRT1 and insulin resistance. Journal of Diabetes and Its Complications, 30(1), 178-183. doi.org/10.1016/j.jdiacomp.2015.08.022

Chong Z, Wang S, Shang C, Maiese K. 2012. Targeting cardiovascular disease with novel SIRT1 pathways. Future Cardiology, 8(1), 89-100. doi.org/10.2217/fca.11.76

Deng L, Li Y., Zhang X, Chen B, Deng Y, Li Y. 2015. UPLCMS method for quantification of pterostilbene and its application to comparative study of bioavailability and tissue distribution in normal and Lewis lung carcinoma bearing mice. Journal of Pharmaceutical and Biomedical Analysis, 114, 200-207. doi.org/10.1016/j.jpba.2015.04.045

Dhanabal P, Kokate K, Ramanathan M, Kumar P, Suresh B. 2006. Hypoglycaemic activity of Pterocarpus marsupium Roxb. Phytotherapy Research, 20(1), 4-8. doi.org/10.1002/ptr.1819

Ding X, Mei W, Huang S, Wang H, Zhu J, Hu W, Ding Z, Tie W, Peng S, Dai H. 2018. Genome survey sequencing for the characterization of genetic background of Dracaena cambodiana and its defense response during dragon's blood formation. PLoS ONE, 13(12), 1-20. doi.org/10.1371/journal.pone.0209258

Fan Y, Yi T, Sze-To M, Zhu L, Peng L, Zhang Z, Zhao Z, Chen B. 2014. A systematic review of the botanical, phytochemical and pharmacological profile of dracaena cochinchinensis, a plant source of the ethnomedicine dragon's blood. Molecules, 19(7), 10650-10669. doi.org/10.3390/molecules 190710650

Gómez-Zorita S, Fernández-Quintela A, Aguirre L, MacArulla, M. T., Rimando, A. M., Portillo, M. P. (2015). Pterostilbene improves glycaemic control in rats fed an obesogenic diet: Involvement of skeletal muscle and liver. Food and Function, 6(6), 1968-1976. doi.org/10.1039/c5fo00151j

Jayaprakasha K, Singh P, Sakariah K. 2001. Antioxidant activity 
of grape seed (Vitis vinifera) extracts on peroxidation models in vitro. Food Chemistry, 73(3), 285-290. doi.org/10.1016/S0308-8146(00)00298-3

Kameswara Rao B, Giri R, Kesavulu M , Apparao C. 2001. Effect of oral administration of bark extracts of Pterocarpus santalinus L. on blood glucose level in experimental animals. Journal of Ethnopharmacology, 74(1), 69-74. doi.org/10.1016/S0378-8741(00)00344-5

Kapetanovic M, Muzzio M, Huang Z, Thompson N, McCormick L. 2011. Pharmacokinetics, oral bioavailability, and metabolic profile of resveratrol and its dimethylether analog, pterostilbene, in rats. Cancer Chemotherapy and Pharmacology, 68(3), 593-601. doi.org/10.1007/s00280010-1525-4

Kosuru R, Rai U, Prakash S, Singh A, Singh S. 2016. Promising therapeutic potential of pterostilbene and its mechanistic insight based on preclinical evidence. European Journal of $\begin{array}{lll}\text { Pharmacology, } & 789, & 229-243 .\end{array}$ doi.org/10.1016/j.ejphar.2016.07.046

Liu H, Lin S, Xiao D, Zheng X, Gu Y, Guo S. 2013. Evaluation of the wound healing potential of Resina Draconis (Dracaena cochinchinensis) in animal models. Evidence-Based Complementary and Alternative Medicine, 2013. doi.org/10.1155/2013/709865

Manickam M, Ramanathan M, Farboodniay Jahromi A, Chansouria N, Ray B. 1997. Antihyperglycemic activity of phenolics from Pterocarpus marsupium. Journal of Natural Products, 60(6), 609-610. doi.org/10.1021/np9607013

Medina-Bolivar F, Condori J, Rimando M, Hubstenberger J, Shelton K, O'Keefe F, Bennett S, Dolan C. 2007. Production and secretion of resveratrol in hairy root cultures of peanut. Phytochemistry, 68(14), 1992-2003. doi.org/10.1016/j.phytochem.2007.04.039

Paul B, Masih I, Deopujari J, Charpentier C. 1999. Occurrence of resveratrol and pterostilbene in age-old darakchasava, an ayurvedic medicine from India. Journal of $\begin{array}{lll}\text { Ethnopharmacology, } & 68(1-3), & \text { 71-76. }\end{array}$
doi.org/10.1016/S0378-8741(99)00044-6

Picard F, Kurtev M, Chung N, Topark-ngarm A, Oliveira De, Leid M, Mcburney W. 2010. NIH Public Access. 429(6993). doi.org/10.1038/nature02583.Sirt1

Ramadori G, Fujikawa T, Anderson J, Berglund D., Frazao R, Michán S, Vianna R, Sinclair A, Elias F, Coppari R. 2011. SIRT1 deacetylase in SF1 neurons protects against metabolic imbalance. Cell Metabolism, 14(3), 301-312. doi.org/10.1016/j.cmet.2011.06.014

Rimando M, Kalt W, Magee B, Dewey J, Ballington R. 2004. Resveratrol, Pterostilbene, and Piceatannol inVacciniumBerries. Journal of Agricultural and Food Chemistry, 52(15), 4713-4719. doi:10.1021/jf040095e

Rizvi I, Mishra N. 2013. Traditional Indian medicines used for the management of diabetes mellitus. Journal of Diabetes Research, 2013. doi.org/10.1155/2013/712092

Satheesh A, Pari L. 2010. The antioxidant role of pterostilbene in streptozotocin-nicotinamide-induced type 2 diabetes mellitus in Wistar rats. Journal of Pharmacy and Pharmacology, 58(11), 1483-1490. doi.org/10.1211/jpp.58.11.0009

Seshadri R. 1972 . Polyphenols of Pterocarpus and Dalbergia woods. Phytochemistry, 11(3), 881-898. doi.org/10.1016/S0031-9422(00)88430-7

Southern N., Blueberry, H. 1990. Cultivar \& germplasm releases. 25(6), 711-712.

Vicente R, Ortugno C, Powell T, Greve C, Labavitch M. 2007. Temporal sequence of cell wall disassembly events in developing fruits. 1. Analysis of raspberry (Rubus idaeus). Journal of Agricultural and Food Chemistry, 55(10), 41194124. doi.org/10.1021/jf063547r

Xu F, Lin B, Zheng X, Chen Z, Cao H, Xu H, Liang H, Weng J. 2016. GLP-1 receptor agonist promotes brown remodelling in mouse white adipose tissue through SIRT1. Diabetologia, 59(5), 1059-1069. doi.org/10.1007/s00125-016-3896-5 